\title{
Hábitos midiáticos e aprendizagem - proposição de hipermídia para o ensino fundamental
}

\author{
Alvaro Martins Fernandes Junior* \\ Siderly do Carmo Dahle de Almeida** \\ Viviane Marques Goi ***
}

\section{Resumo}

Este estudo teve por escopo sugerir elementos para a elaboração de uma hipermídia que estimule o processo de aprendizagem em estudantes que se encontram nos anos iniciais do ensino fundamental. Foi desenvolvida uma pesquisa com alunos nesta etapa, de modo a compreender quais são os hábitos midiáticos destes e que elementos devem compor uma hipermídia capaz de agregar qualidade, prazer e aprendizagem. A pesquisa fundamentou-se em Santaella $(2003,2013)$ no que diz respeito à hipermídia e em autores como Libâneo (2008) quanto à metodologia do ensino e Gardner (1995) quanto às inteligências múltiplas e aprendizagem. A pesquisa realizou-se com um universo que abrange alunos de uma escola pública e outra privada em dois municípios do Paraná. A pesquisa comprova que os alunos se envolvem mais com a aprendizagem quando submetidos a ambientes hipermidiáticos.

Palavras-chave: Educação fundamental. Hábitos midiáticos. Hipermídia e Educação.

\footnotetext{
* Pontifícia Universidade Católica de São Paulo. Doutorando em Educação: Currículo na PUC-SP com bolsa CNPq. alvarojunior777@gmail.com .

** Centro Universitário Internacional Uninter. Doutora em Educação e Currículo pela Pontifícia Universidade Católica de São Paulo (2012) siderly.c@gmail.com .

*** Pontifícia Universidade Católica de São Paulo. Sócia Fundadora da VG CONSULTORIA EDUCACIONAL. Graduada em Informática, Mestre em Modelagem Matemática e Doutoranda no Programa de Tecnologia da Inteligência e Design Digital pela PUC-SP. vmgoi@terra.com.br.
} 


\section{Media habits and learning - proposal of hyper- media for elementary school}

\section{Abstract}

This study aimed at suggesting elements for the elaboration of a hypermedia that stimulates the learning process in students who are in the first years of elementary school. A research was carried with these students in order to understand their media habits and which elements should compose a hypermedia capable of adding quality, pleasure and learning. The research was based on Santaella $(2003,2013)$ regarding hypermedia and other authors such as Libâneo (2008) regarding the teaching methodology and Gardner (1995) regarding multiple intelligences and learning. The research was carried with students from a public and a private school in two cities in Paraná state. The result proves that the students get more engaged in the learning process when submitted to hypermedia environment.

Keywords: Elementary education. Media habits. Hypermedia and Education.

\section{Hábitos midiáticos y aprendizaje - proposición de hipermedia para la enseñanza fundamental}

\section{Resumen}

Este estudio tuvo por objeto sugerir elementos para la elaboración de una hipermedia que estimule el proceso de aprendizaje en estudiantes que se encuentran en los años iniciales de la enseñanza fundamental. Se desarrolló una investigación con alumnos en esta etapa, para comprender cuáles son los hábitos mediáticos de éstos y qué elementos deben componer una hipermedia capaz de agregar calidad, placer y aprendizaje. La investigación se basó en Santaella (2003, 2013), en lo que se refiere a la hipermedia y en autores como Libâneo (2008) en cuanto a la metodología de la enseñanza y Gardner (1995), en cuanto a inteligencias múltiples y aprendizaje. La investigación se realizó con un universo que abarca a alumnos de una escuela pública y otra privada en dos municipios de Paraná. La investigación demuestra que los alumnos se involucran más con el aprendizaje cuando son sometidos a ambientes hipermidiáticos.

Palabras clave: Educación fundamental. Hábitos mediáticos. Hipermedios y Educación. 


\section{Introdução}

O professor Sugata Mitra concebeu as bases para uma pesquisa de vanguarda que envolveu o modo como alunos carentes aprendem, utilizando softwares e jogos de computador. No programa por ele concebido, denominado de Hole in the wall, conhecido em português como "buraco na parede", ele coloca, no final dos anos 90, computadores com acesso à internet em locais habitados por populações indianas menos favorecidas monetariamente e em que os alunos dificilmente teriam condições de acesso a tais tecnologias.

Suas pesquisas explicitam a capacidade que todas as crianças, carentes ou não, têm em utilizar hardwares e softwares, aprendendo rapidamente a manusearem e até mesmo de ensinarem os outros (mesmo os adultos) a fazer uso de tais tecnologias, sendo suficientemente curiosas para aprenderem de modo autodidata.

É ao professor que cabe a tarefa de sistematizar uma práxis empenhada com a transformação social e cultural, que coopere para perpetuar a aproximação necessária entre o saber da experiência e o saber formal, valorizando por igual esses saberes. Percebe-se, assim, que o papel que cabe ao professor não é tão simples, considerando o arco de opções que a profissão oferece em uma sociedade que se encontra em permanente processo de mudança. A educação gera um processo de conscientização e este é um compromisso histórico que permite ao sujeito assumir uma posição de transformador do mundo.

A questão que funda esta pesquisa resume-se à seguinte pergunta: "é possível conceber uma hipermídia que possa promover melhora e efetividade na qualidade da aprendizagem de estudantes que frequentam os anos iniciais do ensino fundamental?"

Nesse sentido, o estudo tem por objetivo propor como pode ser constituída uma hipermídia capaz de agregar qualidade à aprendizagem de alunos dos anos iniciais do ensino fundamental.

Este trabalho foi realizado com alunos que estão nos quintos anos de uma escola pública e outra privada no Estado do Paraná. Importante salientar que quase todos esses estudantes possuem acesso a computadores e à internet. Compreender e analisar os há- 
bitos desse público já se constitui em fator relevante, contudo, fazse primordial compreender como consolidar uma boa comunicação e com qual linguagem estabelecer tal relação para poder compor conteúdo curricular significativo, de bom nível e fácil compreensão.

\section{Metodologia}

A fim de responder ao problema de pesquisa que norteia este trabalho, foram estabelecidas quatro etapas essenciais: o levantamento do arcabouço teórico sobre o uso de hipermídia na educação; a organização do universo amostral da pesquisa; a coleta de informações e a análise dos dados obtidos.

Para a primeira etapa, foi realizada uma pesquisa bibliográfica com o intuito de verificar o que já foi pesquisado sobre o assunto. Considerando-se o que salienta Gil (2010, p. 44), “[...] a pesquisa bibliográfica é desenvolvida com base em material já elaborado, constituído principalmente de livros e artigos científicos". Apresenta como principal vantagem possibilitar ao pesquisador "a cobertura de uma gama de fenômenos muito mais ampla do que aquela que poderia pesquisar diretamente" (GIL, 2010, p. 45).

Já para a segunda etapa, foi escolhida como técnica a pesquisa de campo com aplicação de questionário para a coleta de dados. No caso deste estudo especificamente, foi adotado um estudo exploratório-descritivo combinado, que para Marconi e Lakatos (2008, p. 190):

...são investigações de pesquisa empírica cujo objetivo é a formulação de questões ou de um problema, com tripla finalidade: desenvolver hipóteses, aumentar a familiaridade do pesquisador com um ambiente, fato ou fenômeno, para a realização de uma pesquisa ou modificar e clarificar conceitos. Obtém-se frequentemente descrições tanto quantitativas quanto qualitativas do objeto de estudo, e o investigador deve conceituar as inter-relações entre as propriedades do fenômeno, fato ou ambiente observado.

Assim, a escolha da metodologia e da técnica a ser aplicada considerou a natureza qualitativa e exploratória da pesquisa, com 
foco no corpo discente do quinto ano do Ensino Fundamental de uma escola particular e uma pública no Estado do Paraná. O relatório da pesquisa centrou-se na utilização da hipermídia como prática pedagógica inovadora, possibilitando que se alcance meios mais eficientes de ensinar.

Como técnica de pesquisa, fez-se opção pelo instrumento questionário, que segundo Severino é:

Um conjunto de questões, sistematicamente articuladas, que se destinam a levantar informações escritas por parte dos sujeitos pesquisados, com vistas a conhecer a opinião dos mesmos sobre os assuntos em estudo. As questões devem ser pertinentes ao objeto e claramente formuladas, de modo a serem em compreendidas pelos sujeitos. As questões devem ser objetivas, de modo a suscitar respostas igualmente objetivas, evitando provocar dúvidas, ambiguidades e respostas lacônicas. Podem ser questões fechadas ou questões abertas. No primeiro caso, as respostas serão escolhidas dentre as opções pré-definidas pelo pesquisador; no segundo, o sujeito pode elaborar as respostas, com suas próprias palavras, a partir de sua elaboração pessoal (2007, p. 128).

Esta pesquisa faz uso da estratégia de estudo de caso por, segundo Yin, tratar-se de "investigação empírica que investiga um fenômeno contemporâneo dentro de seu contexto da vida real, especialmente quando os limites entre o fenômeno e o contexto não estão claramente definidos” (2001, p. 32).

Inicialmente, foi apresentado um recurso audiovisual criado de modo exclusivo para o quinto ano do ensino fundamental. Trata-se de um episódio de uma websérie denominada "Conexão 3.0". Consecutivamente, os alunos foram submetidos a um questionário desenvolvido com o Google Docs. As escolas escolhidas - uma pública e outra privada estão em dois diferentes municípios do Estado do Paraná. Ao todo, 59 crianças de escola pública e 49 de escola privada responderam ao questionário.

A estratégia de estudo de caso possibilitou embasar a proposta de uma hipermídia que se estabelece, considerando-se os 
hábitos tecnológicos dos estudantes que participaram efetivamente da pesquisa em questão.

Esta pesquisa utiliza realidade aumentada ao trabalhar com o QR Code em trechos selecionados para tal fim. Isso possibilita que o leitor assista aos fragmentos da websérie. Nesse sentido, é fundamental que o leitor faça uso do aplicativo disponível em aparelhos móveis.

\section{Aprendizagem, tecnologia e hipermídia}

O trabalho didático para o exercício da docência é compreendido como uma atividade que se constrói nas relações humanas, cujo foco principal é o aluno, portanto, é impossível refletir sobre esse tema sem considerar o espaço da sala de aula. A sala de aula é o local onde se processa a aprendizagem, é o lugar onde aprendemos e ensinamos. É, por assim dizer, um reflexo da sociedade.

A aula é, pois, o resultado da integração entre o espaço físico, mobiliários e equipamentos, recursos físicos e humanos onde se propagam ideais e se decodificam signos. Wilson Liberato (2005, p. 67) corrobora com os conceitos emitidos ao conceituar aula como "lição sobre uma determinada disciplina". Acrescenta, porém, que a prática dessa atividade pressupõe de um lado alguém que "solicita ou precisa da lição (o aluno) e de outro um professor que conhece [o assunto] e se propõe a explicá-lo”.

É necessário, entretanto, considerar que, apesar de os sujeitos envolvidos nesse processo (professor e aluno) terem objetivos em comum, aluno e professor trazem consigo para a sala de aula suas experiências de vida e suas próprias concepções sobre o processo de ensino e aprendizagem e de seus respectivos papéis dentro dele.

Portilho, Mesquida e Oliver (2007, p. 185) ressaltam que:

Se assumirmos que educar, no sentido tanto de transmissão quanto de geração de novos conhecimentos, é um componente da condição de ser humano, poderíamos pensar em quão limitante desta própria condição e, por conseguinte, quão desumanizante pode se tornar uma educação calcada na estrita delegação à escola e na dependência de um superprofissional. 
Isso significa que o professor deve buscar métodos, técnicas e recursos diferenciados para possibilitar ao aluno uma aprendizagem significativa e autônoma, pois, "na aula se criam, se desenvolvem e se transformam as condições necessárias para que os alunos assimilem conhecimentos, habilidades, atitudes e convicções e, assim, desenvolvem suas capacidades cognoscitivas" (LIBÂNEO, 2008, p. 177).

Tendo em vista que a Didática é "uma disciplina que estuda os objetivos, os conteúdos, os meios e as condições do processo de ensino tendo em vista finalidades educacionais, que são sempre sociais" (LIBÂNEO, 2008, p. 16) ela deve, junto às tecnologias digitais de informação e de comunicação, buscar diferentes estratégias para o processo de ensino e de aprendizagem, aprimorando-o e tornando-o mais efetivo.

Tendo em vista as transformações que vieram no bojo do uso das tecnologias na educação, faz-se necessário pensar na necessidade de que haja uma crescente evolução no que se relaciona às políticas de implementação dessas tecnologias ao currículo que se interconectam às diversas instâncias que envolvem o sistema educativo. Kenski (2003) avalia que:

Embora a escola não tenha mudado, culturalmente, essas pessoas que aí estão mudaram. E como! Para esses alunos, por exemplo, o professor não é mais a única, nem a principal fonte de saber. Eles aprendem, e aprendem sempre, em múltiplas e variadas situações. Já chegam à escola sabendo muitas coisas. [...] Suas formas de raciocínio não são mais tão lineares introdução, desenvolvimento, e conclusão, mas envolvem aspectos globais em que se encontram o lado efetivo, o cognitivo, o intuitivo. Aprendem fazendo uso de ambos os hemisférios cerebrais, o que significa que elaboram processos mentais em que estão em ação tanto o lado lógico e analítico, quanto os aspectos emocionais, intuitivos e criativos. Possuem comportamentos de aprendizagem mais abrangente e qualitativamente diferentes ao da lógica racional que prevalece nas estruturas das disciplinas que a escola deseja que aprendam (KENSKI, 2003, p. 133).

Almeida e Valente enfatizam que é essencial permitir que todos aqueles que estão envolvidos no processo de educação, a saber 
os gestores, os docentes, os discentes, a equipe de coordenação pedagógica, os membros do conselho da escola, todos devem se mobilizar e elaborar um plano que relacione "infraestrutura, recursos físicos, financeiros e de infraestrutura, tempo e espaço da escola" (2016, p. 37), proporcionando o diálogo entre todos, cabendo especialmente aos gestores tomar a frente do processo de implantação das tecnologias no currículo escolar.

Almeida e Valente (2016, p. 39) analisam que "Os conteúdos e recursos digitais que adentram os espaços escolares e interferem nas práticas de sala de aula se expandem por meio das tecnologias móveis com conexão sem fio à internet". Os autores enfatizam ainda que as tecnologias digitais já fazem parte da vida dos alunos e é isso que suscita a necessidade de se repensar de que modo podemos integrar as tecnologias aos currículos, produzindo e compartilhando as informações veiculadas nas redes e construindo conhecimentos.

A hipermídia desenvolve-se especialmente devido ao crescimento do uso da internet. Santaella (2003) afirma que:

\footnotetext{
...o primeiro fator de definição da hipermídia como rede está na hibridização de linguagens, processos sígnicos, códigos, mídias que ela aciona e, consequentemente, na mistura de sentidos receptores, na sensorialidade global, sinestesia reverberante que ela é capaz de produzir, na medida mesma em que o receptor ou leitor imersivo interage com ela, cooperando na sua realização (SANTAELLA, 2003, p. 95).
}

Gosciola define a hipermídia como um "sistema de comunicação audiovisual e identificada como o meio e linguagem, ou o tecido, que organizam eventos comunicacionais. [..] Um objeto audiovisual que se materializa pelo uso que se faz dela" (2003, p. 17).

Cada nova visita proporciona um novo conhecimento ao leitor, pois é possível trilhar diferentes caminhos para chegar a um mesmo fim, ou a fins diferentes. Importam aqui mais os caminhos que o fim, necessariamente. A cada nova visita à mesma hipermídia, o leitor terá diferentes experiências.

Emissores e receptores, considerando-se um mundo hipermidiático, trocam de papel constantemente. Santaella ressalta que "A 
navegação hipermídia envolve não só compreender as relações entre diferentes mídias, como também a decorrente habilidade de navegação através de diferentes comunidades sociais" (2013, p. 247).

\section{Hábitos dos alunos na internet}

Cabe aqui enfatizar que essa geração, chamada de nativos digitais, sente-se extremamente à vontade frente ao uso de tecnologias digitais. Coelho (2012, p. 90) esclarece que:

Essa geração nasceu, cresceu e se desenvolveu em um período de grandes transformações tecnológicas e, por suas correlações com esse meio digital, adquiriram competências e habilidades que lhes permitem desenvolverem diferentes atividades a partir desses novos meios de comunicação tecnológica.

No contexto desta pesquisa, apresenta-se o acesso do público-alvo ao computador, conforme segue no Quadro 1.

Quadro 1 - Hábitos dos alunos

\begin{tabular}{|l|l|}
\hline & Porcentual \\
\hline Não tenho acesso diário & 21,3 \\
\hline menos de 2 horas & 28,7 \\
\hline de 2 a 4 horas & 25,0 \\
\hline entre 4 e 6 horas & 7,4 \\
\hline mais de 6 horas & 17,6 \\
\hline
\end{tabular}

Fonte: Os autores.

Observa-se que por volta de $80 \%$ do universo pesquisado faz uso diário do computador, e aqueles que não o utilizam diariamente expõem que o fazem quase diariamente. Conclui-se dessa forma, que $100 \%$ dos estudantes permanecem no computador em torno de quatro horas por semana. Esse dado é relevante, pois demonstra que essas crianças utilizam o computador e a internet, e que pensar sobre o desenvolvimento de uma hipermídia torna-se vantajoso. 
Ao se comparar a forma como os estudantes respondem aos questionários, é possível verificar que os alunos das escolas públicas permanecem mais de seis horas por dia no computador, dado maior que o apresentado pelas crianças da escola privada, entretanto, as crianças de escolas privadas acessam diariamente a internet e as de escola pública, quatro ou cinco vezes por semana. Isso valida a hipótese de que, indiferente de estudar em escola pública ou privada, todos os alunos estão igualmente conectados à internet.

Também independente da escola, se pública ou privada, as crianças acessam a internet preferencialmente por seus celulares 19\% contra 17\% em computadores. Apenas 3\% das crianças fazem acesso por tablet. Isso remete refletir que a construção da hipermídia precisa ser adaptável ao meio pelo qual será ativada.

O público-alvo da pesquisa estuda de distintas formas, ora utilizando tecnologias digitais, ora não. O Quadro 2 apresenta alguns dados que demonstram que a maioria dos alunos prefere fazer buscas no Google do que pesquisar no livro didático ou em outros meios.

Quadro 2- Como os alunos estudam

\begin{tabular}{|lrrr|}
\hline & \% Pública & \% Particular & \% Geral \\
\cline { 2 - 5 } Faço buscas pelo Google & 17,0 & 30,6 & 24,5 \\
Leio o livro didático & 21,6 & 25,0 & 23,5 \\
Prefiro livros com mais figuras & 18,2 & 11,1 & 14,3 \\
Faço buscas pelo YouTube & 9,1 & 17,6 & 13,8 \\
Prefiro livros sem muita figura & 9,1 & 8,3 & 8,7 \\
Não estudo em casa & 12,5 &, 9 & 6,1 \\
Uso o computador mas não & 8,0 & 3,7 & 5,6 \\
acesso a internet & & & \\
Outros & 4,5 & 2,8 & 3,6 \\
\hline
\end{tabular}

Fonte: Os autores. 
Outra questão relevante se estabelece sobre a afirmação de que os alunos buscam tutoriais na internet quando desejam aprender alguma coisa - 77\% do público analisado afirma procurar na internet auxílio para aprender alguma coisa. Ainda 23\% das crianças relatam já ter efetuado tutoriais para dispor na internet.

Ainda se considerando os hábitos dos alunos com relação à internet, foi perguntado quais são as suas buscas - 23\% desses alunos a buscam para jogar, 19,6\% olham vídeos no YouTube e 15,4\% ouvem música pelo YouTube. Contudo, quando se efetivam comparações entre as informações sobre jogos nas escolas pública e privada, 29,4\% dos alunos estão na escola pública e 18,6\% na escola privada. Quanto a vídeo no YouTube, os alunos de escola privada ficam na liderança, representando $21,6 \%$, enquanto as crianças da escola pública ocupam 16,8\%, invertendo-se as posições.

Quadro 3 - O que fazer na Internet?

\begin{tabular}{|l|r|r|r|}
\hline & Pública (\%) & Privada (\%) & \multicolumn{1}{c|}{ Geral (\%) } \\
\hline Jogar & 29,4 & 18,6 & 23,1 \\
\hline Ver vídeos no YouTube & 16,8 & 21,6 & 19,6 \\
\hline $\begin{array}{l}\text { Ouvir músicas no You- } \\
\text { Tube }\end{array}$ & 14,3 & 16,2 & 15,4 \\
\hline Conversar com amigos & 15,1 & 12,0 & 13,3 \\
\hline Estudar & 10,9 & 13,2 & 12,2 \\
\hline Acessar redes sociais & 5,0 & 9,6 & 7,7 \\
\hline $\begin{array}{l}\text { Tirar dúvidas que tive } \\
\text { na aula }\end{array}$ & 7,6 & 7,2 & 7,3 \\
\hline Outros &, 8 & 1,8 & 1,4 \\
\hline
\end{tabular}

Fonte: Os autores.

Ser conhecedor de tais hábitos colabora para fundamentar a proposta dessa hipermídia e o fato de as crianças já estarem adaptadas e gostarem torna a hipermídia um material significativo para o desenvolvimento do processo de ensino e de aprendizagem. 
A história do episódio pensado para este estudo e apresentado às crianças começa com a menina que faz o papel de Bruna na websérie conversando com Matheus pelo celular que a informa que comprou por três mil reais os convites para determinado show. Entre idas e vindas do presente para o passado e para o futuro, o episódio apresenta a importância do uso da pontuação correta para a compreensão de textos. Acessando o QR Code a seguir, é possível assistir o episódio integralmente.

Figura 1: QR Code do episódio

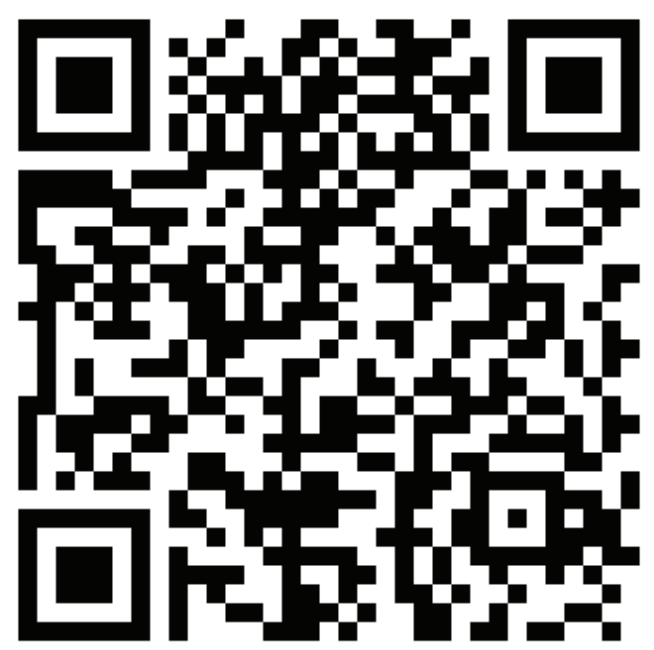

A websérie Conexão 3.0 foi idealizada considerando-se os conteúdos que os alunos dos quintos anos precisam ter para responder à Prova Brasil.

Bairon e Petry destacam que uma questão fundamental para que a hipermídia possa se conectar e ser compreendida por seus usuários é a indicação de uma metáfora, pois "seu funcionamento associativo por similaridade e contiguidade, mimetizando o próprio funcionamento das ações humanas" (2000, p. 10). 
Após assistir ao episódio, o mesmo obteve 100\% do aceite dos alunos e os mesmos disseram que, caso o "Conexão 3.0" efetivamente existisse, $98,1 \%$ fariam uso do mesmo para tirar dúvidas, fazer pesquisas e se entreter com as webséries.

É importante salientar que como os testes de QI analisavam basicamente a inteligência lógico-matemática das pessoas, nos anos 80 Howard Gardner, cientista da Universidade de Harvard, passou a questionar tal método, propondo então, a existência de múltiplas inteligências, ressaltando que certas pessoas têm mais facilidade para aprender matemática, outras têm mais facilidade para a música ou para os esportes e que isso, não diminui em nada a sua inteligência, trata-se apenas de diferentes formas de inteligência.

A Teoria das Inteligências Múltiplas, desenvolvida como uma explicação da cognição humana, além de reconhecer as diversas e independentes facetas que a compõem, ainda, preconiza a interdependência entre duas ou mais delas. Isto se explica pelo fato de que cada uma das formas de inteligência pode ser canalizada para outros fins, isto é, os símbolos vinculados àquela forma de conhecimento podem migrar para outras, denotando as características de independência e interdependência já salientadas (GASPARI; SCHWARTZ, 2002, p. 263).

Desse modo, em tal teoria, reconhece-se a possibilidade de sermos dotados não apenas de um tipo de inteligência, mas de um conjunto delas, que nos ajudam na construção de nosso conhecimento de modo específico e particular. A esse respeito, Antunes evidencia que a inteligência "tem a propriedade de selecionar a maneira melhor de compreender as coisas, a melhor saída para resolver problemas" (1998, p. 17).

Com isso e salientando-se as possibilidades de múltiplas formas de aprender que a hipermídia oferece, os autores desta pesquisa levantam qual o conteúdo que deve compor tal material. Para isso, tomam por base o currículo escolar para esse nível de ensino e o conteúdo cobrado na Prova Brasil.

Conforme se verificou, 100\% dos alunos interessaram-se pelo episódio. Determinou-se, então, categorias que permitissem 
perceber quais os motivos que mais incitaram os alunos a gostar do mesmo:

- lúdico: Para esta categoria, admitiram-se palavras como interessante, legal, engraçado, divertido, nas respostas dos alunos

- $\quad$ educativo: Respostas que indicassem que o aluno aprendeu com a websérie

- originalidade: Respostas que contemplassem palavras como original e criativo figuram nesta categoria.

Continuando o estudo das categorias de análise, observa-se "lúdico" como um dos termos mais encontrados, representando $73 \%$ dos que foram colocados em contato com a websérie. Dos respondentes, $7 \%$ disseram que a série era original e $20 \%$ a consideraram educativa. Inserir conteúdos do currículo na hipermídia possibilita que os alunos aprendam de modo lúdico, sem nem mesmo perceber que estão aprendendo.

\section{Considerações finais}

Esta pesquisa pretendeu responder à questão "é possível conceber uma hipermídia que possa promover melhora e efetividade na qualidade da aprendizagem de estudantes que frequentam os anos iniciais do ensino fundamental?" O universo da pesquisa foram os alunos que estudam no ensino fundamental, especialmente os do quinto ano, por se tratar daqueles que devem obrigatoriamente realizar a Prova Brasil.

Por meio da análise de dados do estudo, observou-se que dos 108 alunos pesquisados, $80 \%$ ficam de duas a oito horas por dia em seu computador, seja jogando - o que caracterizou $23,1 \%$ dos respondentes, pesquisando no Google - 24,5\% dos respondentes, ou olhando vídeos no YouTube - 19,6\%.

Como os autores possuíam a hipermídia apenas no plano das ideias, a solução foi expor o público-alvo a um material audiovisual elaborado especificamente para os estudantes do quinto ano, e assim como um acontecimento se torna uma série, e um livro se 
constitui como base para a elaboração de um filme, foi possível verificar que material audiovisual é caminho amplo e forte para a idealização e concepção de uma hipermídia.

O que propiciou rigor a essa afirmação foi a pesquisa realizada e exposta neste trabalho, onde a análise das respostas dos questionários aproximou os autores da certeza de que os elementos que compunham o audiovisual poderiam também estar presentes em uma hipermídia.

A hipermídia se estabelece e acontece sob uma metáfora, e de modo a verificar se o laboratório poderia se consistir como esse cordão umbilical para a hipermídia a se propor, foi questionado aos alunos se eles se afeiçoaram ao episódio e o porquê, e principalmente, se utilizariam, como o fazem os personagens da série, o laboratório para estudo e contato com os cientistas. Todos os alunos que responderam o questionário aprovaram a série, assinalando que gostaram e, na questão de uma existência hipotética do laboratório, 98\% afirmaram que o usariam caso existisse. Essas assertivas contribuíram para asseverar aos autores que o laboratório poderia se consistir enquanto metáfora da hipermídia.

A questão que verificou o porquê dos alunos terem gostado do episódio teve suas respostas organizadas em categorias: ludicidade, educacional e originalidade. A ludicidade representou $73 \%$ dos motivos das crianças terem gostado do episódio. Das respostas, $20 \%$ estão inclusivas na categoria educacional, ou seja, de seu caráter educativo e, por fim, 7\% afirmaram que a originalidade do material foi o que os motivou a ter apreço pelo episódio.

O apontamento por parte dos respondentes de que gostaram do que viram pelo fato de terem aprendido algo, bem como, a conivência e exaltação dos alunos pelo laboratório, deu força à estratégia inicial: atribuir conteúdos curriculares situados na BNCC à hipermídia. Essa fusão da ludicidade proporcionada pelo audiovisual com conteúdos educacionais mostrou-se hábil a nortear a construção de uma hipermídia composta pelas habilidades e competências elencadas na Base Nacional Curricular Comum. 
O estudo debateu o senso comum ao pesquisar em campo os hábitos televisivos do público-alvo, informação que pode contribuir tanto para a construção da hipermídia Conexão 3.0 quanto para proposições de outras tecnologias e metodologias de aprendizagem para o público estudado.

\section{Referências}

ALMEIDA, Maria Elizabeth Bianconcini de; VALENTE, José Armando. Políticas de tecnologia na Educação Brasileira: histórico, lições aprendidas e recomendações, 2016. Disponível em: <http://www.cieb.net.br/wp-content/uploads/2016/12/CIEB-Estudos-4-Politicas-de-Tecnologia-na-Educacao-Brasileira. pdf>. Acesso em: 4 ago. 2017.

ANTUNES, C. A inteligência emocional na construção do novo eu, 3. ed. Petrópolis: Paz e Terra, 1998.

BAIRON, S.; PETRY, L. C. Hipermídia psicanálise e História da Cultura: making of. Caxias do Sul; São Paulo: EDUCS; Editora Mackenzie, 2000.

COELHO, P. M. F. Os nativos digitais e as novas competências tecnológicas. Texto livre: linguagem e tecnologia. Disponível em http:/ /www.periodicos.letras. ufmg.br/index.php/textolivre/article/view/2049/7254 Acesso em 26 maio 2017.

GASPARI, Josset Campagna de; SCHWARTS, Gisele Maria. Inteligências múltiplas e representações. Psic.: Teor. e Pesq. Brasília, v. 18, n. 3, p. 261-266, dez. 2002. Disponível em <http://www.scielo.br/scielo.php?script=sci_arttext\&pid=S0102$37722002000300004 \& \operatorname{lng}=$ pt\&nrm=iso $>$. Acesso em 11 maio 2017.

GIL, A. C. Como elaborar projetos de pesquisa. São Paulo: Atlas, 2010.

GOSCIOLA, V. Roteiro para as Novas Mídias: do Game à TV interativa. São Paulo: Editora Senac São Paulo, 2003.

KENSKI, V. M. Tecnologias e ensino presencial e a distância. São Paulo: Papirus, 2003.

LIBÂNEO, José Carlos. Didática. São Paulo, Cortez, 2008.

LIBERATO, Wilson. Transversalidade. Conexão Ciência: R. Cient. FUOM, Formiga, v. 2, n. 1, p. 67-81, jan./jul. 2005 
MARCONI, Marina de Andrade; LAKATOS, Eva Maria. Fundamentos de metodologia científica. São Paulo: Atlas, 2008.

PORTILHO, E. M. L.; MESQUIDA, P.; OLIVER, C. Da formação de professores à condição de educador. Rev. Educação e Linguagem. Disponível em https:// www.metodista.br/revistas/revistas-ims/index.php/EL/article/view/132/142 Acesso em 26 maio 2017.

SANTAELLA, L. Cultura e artes do pós humano: da cultura das mídias à cibercultura. São Paulo: Paulus, 2003.

SANTAELLA, L. Comunicação ubíqua: Repercussões na cultura e na educação. São Paulo: Paulos, 2013.

SEVERINO, Antonio Joaquim. Metodologia do trabalho científico, 23. ed. São Paulo: Cortez, 2007.

YIN, R. K. Estudo de Caso, 2. ed. Porto Alegre: Artmed, 2001.

Submetido em: 18-3-2018

Aceito em: 28-3-2018 